

\title{
Interpretation and Paradigm in Architectural Metatheory
}

\section{Dimitris Hartonas $^{1 *}$ and Nikolaos Ion Terzoglou ${ }^{2}$}

${ }^{1}$ Wolfson College, Barton Road, 3CB 9BB, Cambridge, Cambridgehire, United Kingdom. E-mail: dh646@cam.ac.uk ${ }^{2}$ National Technical University of Athens - School of Architecture, Patission. E-mail: niterzoglou@arch.ntua.gr

\section{Article Info}

Volume 1, Issue 2, September 2021

Received : 12 June 2021

Accepted : 18 August 2021

Published : 05 September

doi: 10.51483/IJARP.1.2.2021.28-36

\begin{abstract}
This study stands in-between two distinct areas, modern epistemology and architectural theory and interpretation. A dual approach is being carried out in an attempt to transfer concepts and methods of approach from the field of philosophy of science to that of architectural discourse. By examining architecture at a meta-theoretical level, i.e., making architectural theory itself the object of theorizing, it is attempted to transcribe epistemological concepts, tools and conceptual schemas into the field of architectural interpretation and theory. The study's objective is to outline a suitable framework for examining the evolution of architectural theory itself and for understanding its shifts. More specifically, we attempt to formulate a model that will allow for a more systematic approach of the course of architectural interpretation, theory and criticism. The main point of the study, stated and documented in detail, is that an architectural interpretation can be regarded as a (dominant) paradigm, much as a scientific theory can. Interpretations change over time, reflecting changes of value systems underlying a general view of architecture, rather than having a dependence on the specific object of interpretation. A concept of an "interpretative paradigm" (a hermeneutical paradigm) is proposed, regarded as a system of beliefs associated with a broad view of architecture, which determines the direction followed by the interpretations of distinct works. Hermeneutical paradigms do not constitute timeless invariants, but they are transformed and modified over time. The transition process by which such shifts occur, following a paradigm crisis, is analyzed in this article by describing a mechanism of theoretical/ interpretative paradigm shift in architecture. The study is concluded with a brief discussion of the notion of "progress" in architectural theory and interpretation, building on similar contribution in the philosophy of science.
\end{abstract}

Keywords: Interpretation, Paradigm, Meta-theory, Epistemology, Criticism, Theory

(C) 2021 Dimitris Hartonas and Nikolaos Ion Terzoglou. This is an open access article under the CC BY license (https://creativecommons.org/licenses/by/4.0/), which permits unrestricted use, distribution,

and reproduction in any medium, provided you give appropriate credit to the original author(s) and the source, provide a link to the Creative Commons license, and indicate if changes were made.

\section{Introduction}

This research lies within the metatheory of architecture. It investigates the modalities of different models of architectural thinking or thinking about architecture. Laying out objectives, clarifying values, proposing methods, approaches and evaluation criteria —or even putting forward views that critically reject one or more of the above-is what an architectural theory is about. Metatheory and, in particular, architectural metatheory, focuses on investigating the role played by

\footnotetext{
* Corresponding author: Dimitris Hartonas, Wolfson College, Barton Road, 3CB 9BB, Cambridge, Cambridgehire, United Kingdom.E-mail:dh646@cam.ac.uk
}

2788-5046/@ 2021. Dimitris Hartonas and Nikolaos Ion Terzoglou. This is an open access article distributed under the Creative Commons Attribution License, which permits unrestricted use, distribution, and reproduction in any medium, provided the original work is properly cited. 
such architectural views (theories) and their evolution. Put generally, a theory bears on some specific aspect of the knowable. By contrast, the object of metatheoretical investigation is the theories themselves, as these have been developed in connection to the aspects of the knowable that they are about. Epistemology or philosophy of science, embarks on an analysis of the ways that natural science theories are formed, established and, eventually, get abandoned by scientists.

This research study aims at investigating and evaluating the impact of concepts, conceptual schemes and tools from the area of contemporary epistemology to that of architectural metatheory. It is our belief that the adaptation of epistemological models to architecture and its metatheory can provide tools that are suitable for the understanding of the evolution of architectural theorizing. We shall therefore first briefly present some of the main ideas advanced in the context of the philosophy of science, subsequently turning to presenting efforts that have been made to articulate an architectural metatheoretical discourse that is based on the former. In doing this we also advance our own view and argue for it in the particular case of architectural criticism. While adhering, by and large, to Kuhn's views, we find that Kuhn's idea of a "revolutionary" change fails to shed light on the process of change itself. Therefore, this study focuses on the analysis of the transition period between Kuhnean paradigms.

The decisive turning point in modern epistemology, as commonly acknowledged, is Thomas Kuhn's The Structure of Scientific Revolutions published in 1962 (Kuhn, 1962). Kuhn introduces the notion of scientific Paradigm and argues extensively for a discontinuous evolution of the natural sciences. This is in marked contrast to the up to then reigning views of the logical positivists, as well as of Karl Popper's falsificationist approach (Popper, 1959). In the received positivist view, the truth of scientific claims was to be established by means of scientific experiments aiming at providing a verification of the theory's conjectures and predictions. Popper (1959), on the other hand, insisted and argued extensively that the mark of a truly scientific claim lies in the possibility to lay out the conditions of its possible falsification through experimental testing. Kuhn's structure of scientific revolutions is an elaborately documented attempt to overturn the received views and establish, instead, the view that evolution in science is made possible by the occurrence of scientific revolutions, understood as comprehensive world-view changes that have nothing to do with establishing truth, but reset the way we conceive physical reality. Kuhn's relativistic views raised the expected criticism, notably by Imre Lakatos (Lakatos and Musgrave, 1970; Lakatos, 1978), while also providing support to Paul Feyerabend's more daring views (Feyerabend, 1975), attempting to establish that any distinction between myth and science is plainly arbitrary. Kuhn's and Feyerabend's views, abolishing the idea of scientific evolution as approximation of truth, are in need of accounting in some way for the problem of progress. Larry Laudan recognizes the issue and offers a detailed account of it in his Progress and its Problems (Laudan, 1978), reformulating the progress problem as a problem to be understood in terms of rational choices made by scientists in their theoretical endeavors.

There have been some attempts to adapt and restate, in the context of architectural metatheory, tools and conceptual schemes originating in epistemological views about scientific evolution. Panos Tzonos (Tzonos, 1984; Tzonos, 1972) attempts to draw a parallel between Kuhn's notion of a Paradigm and his own proposed concept of a value system in architecture, while Juan Pablo Bonta (Bonta, 1975; Bonta, 1979) is rather explicitly inspired by Kuhn's views of scientific revolutions when he attempts to trace the shifts that one observes in the interpretation of an architectural work, focusing for this purpose on the celebrated example of the Barcelona Pavilion. In the same vein, Stanford Anderson and his school in the department of architectural history, theory and criticism in M.I.T., engage in articulating a framework for the study of architectural theory (Anderson, 1984), this time leaning on Lakatos's epistemological doctrine (Lakatos and Musgrave, 1970). Paul-Alan Johnson, finally, publishes in 1994 a study (Johnson, 1994), the aim of which is to draw the connections between the modes of evolution of architectural theory and Feyerabend's views of an anarchic research that proceeds by rejecting even the most basic of the received theoretical assumptions in science.

As stated already, the objective of the present study is to outline a metatheoretical framework for the analysis and understanding of the modalities of change in architectural theory. Our aim is not to advance a novel view within the theory of architecture. Rather, it is to establish an appropriate metatheoretical framework for the study of architectural thinking. The framework that we seek to outline can contribute in better understanding theory, interpretation and criticism within architecture. In this context, we shall advance and argue for the view that there is an analogy to be drawn between Paradigm and architectural Interpretation. Part of our objectives is also to better understand and sketch a mechanism by which a shift in the theoretical (interpretative) architectural Paradigm is brought about. We shall attempt, in this respect, to identify the partial processes that are involved in making up the structure of such a mechanism and this, we believe, contributes in providing an understanding of the ways in which these shifts are realized. 


\section{The Structure of Architectural Revolutions}

In the late seventies, Geoffrey Broadbent announced the publication of a book with the title The Structure of Architectural Revolutions, which has been nevertheless never published. Despite this, the announcement itself makes a clear connection between architectural metatheory and the view of scientific change proposed by Kuhn (1962). But there are also published attempts with similar objectives, namely the published work of Tzonos (1984) and Bonta (1979). To better understand the views of these authors, we first turn to a quick review of Kuhn's ideas in the philosophy of science.

\subsection{The Structure of Scientific Revolutions}

The scientific Paradigm is no doubt the central notion in Kuhn's epistemological work (Kuhn, 1962). A scientific Paradigm, in Kuhn's view, constitutes a framework encompassing all the commonly accepted views on a subject, a structure that determines the direction of future research, as well as the ways such research is to be conducted. It hosts laws, theories, applications, practices and experimental setups all at once. A Paradigm embodies and proposes a world view. Once adopted by a scientific community, it establishes itself as the dominant Paradigm within which scientific research is conducted. According to Kuhn, science is then said to go through its normal phase. During this normal science phase, the limitations of the Paradigm are being investigated, its application scope is being extended and, in this process, some of the parameters set by the Paradigm are corrected and refined. In brief, normal science is the commonly perceived image of scientific activity.

Nature's violation of some of the Paradigm's predictions is what Kuhn calls an anomaly. Though the emergence of anomalies does not result in doubting the scientific Paradigm, the accumulation of nature-theory clashes may lead to a state of crisis. The realization by the scientists that the Paradigm is in crisis is a pre-requisite, says Kuhn, for any eventual theory change. Repeated theory change, put forth in an effort to eliminate observation-theory disagreement, leads to new anomalies, now at different points. In time, the rules of normal science lose their initial crisp clarity and they become rather confused.

This state of crisis, however, does not lead to giving up the Paradigm. Validity of the Paradigm is not lost until a competing, alternative Paradigm emerges to assume a dominant place. This Paradigm shift is what Kuhn calls a scientific revolution.

This model of scientific change is best exemplified in the Copernican revolution in astronomy. The predecessor of the Copernican astronomical model, Ptolemaic astronomy, marked considerable success in predicting the positions of celestial bodies while going through its own phase of normal science. Gradually, anomalies began to appear and accumulate, as astronomical predictions using the Ptolemaic system did not always agree with observations. Continuous reform rendered the Ptolemaic system of superimposed circles extremely complicated and led to a loss of its internal consistency. The Ptolemaic Paradigm was led to crisis. The recognition by the scientific community of such a state of crisis has been a necessary prerequisite for the ensuing scientific revolution, the Paradigm shift that replaced the Ptolemaic by the Copernican system.

For Kuhn, the decision to change Paradigm is not the result of logical reasoning, but one better described in terms of faith conversion. It never relies on a comparison of theory with the observable world, or on a comparison of theories between themselves. The new tradition resulting after a scientific revolution is in fact, in Kuhn's words, incommensurable with the preceding tradition that it replaced. Kuhn mentions in this regard that laws that may appear in one tradition impossible to verify by experiments, may appear to be self-evident in another, falling under a different Paradigm. The shift from one Paradigm to another is much like a gestalt switch. What appears to be a duck in a certain moment may appear to be a rabbit in the next moment! A gestalt visual switch may go back and forth forever. The difference with a Paradigm shift is that once the new view of reality is established, the old one is rejected and abolished. Kuhn's view has not gone without criticism. In fact, it has been argued that the very notion of a Paradigm itself is ambiguously used by Kuhn. Margaret Masterman (1970) pursued a systematic study of the different meanings the word Paradigm had in Kuhns Structure of Scientific Revolutions, suggesting that the term was in fact used in at least twenty-one different shades of meaning.

\subsection{Kuhn and the Human Sciences}

The wide range of meanings of the term Paradigm and the ample margins of different interpretations formed the decisive factor that paved the way towards borrowing and using the term in areas that were initially unintended, such as the human sciences. In human sciences, too, the notion of a Paradigm provides a conceptual tool for the understanding of phenomena relating to changes, shifts to new views, periods of continuity as well as discontinuity in the modes of 
thinking of the researchers. An example of such an unintended, by Kuhn (1962), application can be found in Michael Overington's paper, "The Scientific Community as Audience: Toward a Rhetorical Analysis of Science” (Overington, 1977). In his essay, Overington discusses the notion of "scientific knowledge" in the fields of rhetoric and sociology by referencing Kuhn's analysis and conceptual tools. Keith Percival, on the other hand, employs a more critical approach towards the application of Kuhn's ideas in social sciences in his article "The Applicability of Kuhn's Paradigms to Social Sciences" (Percival, 1979). Percival argues that the notion of the Revolution, rather than that of the Paradigm can be used to establish a less tenuous connection between natural sciences and the humanities. Both the degree and the way in which Kuhn's analysis can be applied to the human sciences is a subject of debate. Regardless, Kuhn's perception of the human sciences as non-mature scientific fields, did not prohibit a discussion of such fields in Kuhnean terms.

Regarding human sciences as sciences that have not reached a mature stage, as Kuhn holds, it is implied that there cannot be in these cases any notion of a dominant Paradigm. Despite such a widely held view, we will argue that in as far as architectural interpretation is concerned the fact of the coexistence of many antagonistic Paradigms is only observed at certain stages of development. Both in traditional human sciences (sociology or psychology) as well as in what concerns architectural interpretation it appears that changes of Paradigm are more frequent than in physical sciences. The in-depth, structural change in the ways the architectural phenomenon is viewed is not as rare as in physical sciences, but this does not exclude the possibility of identifying discrete Paradigms and their succession in time.

\subsection{Four Value-Systems in the Contemporary Theory of Architecture}

An attempt to import Kuhn's views of scientific revolutions in the metatheory of architecture was made by Tzonos (1972). Tzonos attempts to establish an analogy between scientific Paradigms and architectural Paradigms, defining the latter as architectural value systems. For Tzonos, in the period from the end of the nineteenth century to 1972, when he publishes his study, there have been four distinct value systems corresponding to distinct sub periods. More precisely, Tzonos identifies these four periods as being characterized by an aesthetic, a technological, a scientific and a sociological approach to architecture. Tzonos, however, though referring to Kuhn, has a notably different conception of theory change comparing to that expounded in the Structure of Scientific Revolutions. By a sharp contrast to the Kuhnean process of conversion from one Paradigm to the next, in the case of value systems and according to Tzonos, the old value system is not totally abandoned by the architectural community. The shift to the new value system means that the main body of design decisions, or the focus of architectural criticism, has been moved to a new ground, though the old value system continues to be part both of the decision making and of the critical appraisal of architectural works.

\section{Architecture and its Interpretation: Kuhn and Bonta}

In his book Architecture and its Interpretation, Juan Pablo Bonta aims at providing a meta-theoretical account of the changes in the interpretation of the Barcelona Pavilion (Bonta, 1979). Adopting an analytical rather than a historical point of view, Bonta attempts to identify and categorize the distinct phases of the interpretation of the pavilion and to clarify the changes that took place. Bonta adopts the view that the objective of architectural interpretation is not to attain some solid, scientific knowledge. Rather, Bonta holds, interpretations are subject to the general tendencies of the history of ideas and he draws a parallel with Kuhn's epistemological views at the end of his study, from which we quote:

"We interpret buildings in certain ways because, in doing so, we can throw light upon aspects of the world in which we live. Interpretations are discarded - like forms - not so much because we get bored with them, but because they cease to fulfill the initial, cultural role, and new interpretations more closely in line with contemporary interests are bound to arise in substitution of the old ones."

In the sequel, we proceed to an explicit re-structuring of Bonta's work around the conceptual tools introduced by Kuhn in epistemology. The aim is to draw an explicit parallel between the metatheory of architecture and the philosophy of science.

\subsection{Interpretation, Paradigm and Interpretative Paradigm}

It is not hard to see that in the course of history both experts and perhaps less experts advance evaluative judgments for architectural works, judgments that may at times be completely at variance with one another. For example, Banham (1969; 1960) refers to the floor plan of Gerrit Rietveld's Schroeder House as indifferent, while Broadbent (1993), to the contrary, writes that it is the most worthy element of the design. The disagreement is apparently complete. The ways that the building is examined by the two authors are different and their respective evaluation criteria are incommensurable, resulting in totally different evaluations. Similarly, Zevi $(1957$; 1964) claims that amongst all of Le Corbusier's buildings 
it is the Villa Savoye that is most representative of the principles stated by Le Corbusier in his writings while, to the contrary, Summerson (1963) "sees" a divergence between Le Corbusier's design and writings. The divergent evaluations demonstrate that each of the distinct views constitutes an interpretation of the built work, a decoding of the message that the creator of the work intended to send.

The process of interpretation and/or evaluation of an architectural work is based on a set of conventions and respective values. Based on the evaluation of the work, architectural critics identify and acknowledge each time certain of the features of a work at the expense of others in a process that is not always thought out. In the case of the Barcelona Pavilion, which is the object of Bonta's analysis, the interpretation that was eventually clearly formed and which became dominant and was spread to the architectural community through the analyses of Banham $(1969 ; 1960)$ Blake (1960), Fitch (1961; 1976), as well as Drexler, Benevolo, Scully, Carter, as reported in Bonta (1979), during 1960-61 can be summed up to six basic points:

1. The pavilion provided a new kind of spatial experience, often referred to as flowing space.

2. The design explored the expressive potential of what came to be known as free-form plan.

3. Having little to exhibit in its interior, the building itself became the object exhibited.

4. The building highlighted visual qualities of different artistic movements.

5. It symbolized the recovery of post-war Germany and it reflected the political climate within which modern architecture became possible.

6. The pavilion was a work of art, the best building of its decade, one of the masterpieces of twentieth century architecture.

Despite the extensive effort for an interpretation and critical analysis of the pavilion some aspects were neglected. Indeed, it took no less than ten years for Fitch himself, one of the critics that helped shape through his writings the interpretation that came to be standard in the sixties, that the dominant interpretation totally neglected to deal with issues of environmental comfort. This demonstrates that, depending on the value system of the critic, some aspects of the architectural work can be neglected in the interpretation process. The set of value beliefs that is responsible for weighing certain aspects more than others may be designated by the term Interpretative Paradigm. It is the interpretative paradigm that determines the overall direction of the interpretation and criticism of architecture.

Broadbent (1970) mentions that architectural works are interpreted in accordance with the spirit of the times (Zeitgeist). Not the time of construction, but that of the interpretation. Broadbent argues for his point by taking as an example Rietveld's Schroeder house. For years, the building was understood as an exercise with infinite, never ending space. It focused on the relationships between internal and external space and on the impact of fine arts on architecture.

"The most remarkable feature of all, which went unremarked in the 1920s and has hardly been noticed since, is in fact the first-floor plan. [...] The upper floor can be opened into one clear space, closed into five individual rooms, or left in a variety of states in between. It is, in fact, the first cybernetic house plan to be built in Western Europe, and there is not the slightest doubt that if it had been built in 1964 instead of 1924, it would be recognized as such".

In a sense, Broadbent was not quite right. The cybernetic dimension of the house was recognized already in the 1920 s, even though the term was not yet used. In the beginnings of the $20^{\text {th }}$ century adaptability, self-regulation and cybernetics were not issues that were valued in any sense. In any case, interpretations are determined by broader tendencies that have not much to do with the architectural works under interpretation. Changes in these broader value systems lead to changes in the interpretation of architecture, not of isolated works, but of architecture at large. In other words, they lead to shifts of the interpretative paradigm in architecture. In architecture, as in the case of hard science, a view consisting of value beliefs is adopted by a sizable part of the architectural community and this marks the paradigm shift. For Kuhn (1962) the dominance of one world view over others is a prerequisite for the passage to the normal science phase, during which the potential of the Paradigm is explored and tested. This is not a view that went uncontested and Laudan, in particular, has criticized it on the grounds that it does not appear to be supported by real historical facts (Laudan, 1978). In architecture, it is rather clear that the condition of complete dominance of one interpretative paradigm does not hold. By contrast to the Kuhnean view, the relationship between distinct Paradigms in their historical interconnection is more complicated. But it does remain true that the shift towards a new interpretative paradigm in architecture brings with it a radical re-interpretation of the past, much as this happens with scientific paradigms. 


\subsection{Paradigm Shift: Canonical and Pre-Canonical Interpretations}

Architectural works that come to enjoy recognition, such as Mies's pavilion, go through an initial phase of disregard to one of positive evaluation and interpretation. Multiple interpretations are proposed, isolated judgments that do not enjoy the acceptance of the architectural community. Through an analysis of often incomparable interpretations, according to Bonta (1979), some interpretations become more widespread and they eventually determine the way that the work is being broadly perceived. Bonta proposes to use the term pre-canonical interpretation as opposed to the eventually broadly accepted canonical interpretation. Contrary to the former, it is the latter that has the acceptance of the architectural community, or at least of a sizable part of it.

Pre-canonical interpretations appear both as interpretation efforts of an architectural work that emerges out of disregard, as well as re-interpretations of works for which a canonical interpretation had been established. Pre-canonical interpretations of the first kind are, for example, the initial interpretations of the Barcelona Pavilion, which paved the way for the pavilion to first emerge out of total lack of recognition and eventually receive an established, canonical interpretation. To give some examples of pre-canonicity in interpretation, we may mention Hitchcock's reaction towards the pavilion, merely viewing it as a useful experiment that demonstrates the potential of Mies van der Rohe as an architect (Hitchcock, 1929; Hitchcock, 1958). Similarly, for the interpretations of Rietveld's Schroeder house that focus on elements of self-regulation, leading several decades later to a concept of a cybernetic house and becoming part of the canonical interpretation of the work.

What Bonta (1979) regards as the broad acceptance of a canonical interpretation, we propose, can be regarded as the establishment of a new interpretative paradigm in architecture, established largely the same way that Kuhnean scientific paradigms obtain dominance in the scientific community. What is markedly different in architecture, comparing to the Kuhnean account of scientific paradigm shift, is that more than one paradigm may be codominant, witness the nearly coexistence of three different interpretations of Gothic architecture, the rational, the expressionist and the spatial canonical interpretations. Establishment (of a canonical interpretation) is followed by dissemination and by a normal science phase, during which the new paradigm is refined.

The new paradigm is often responsible for drawing attention to works that remained unnoticed, or even received a negative criticism, leading to their re- interpretation. Thus Hitchcock $(1929 ; 1958)$, three decades after his first evaluation of the pavilion revises his criticism and advances the view that the pavilion is "one of the few buildings by which the twentieth century might wish to be measured against the great ages of the past".

\section{Towards an Interpretation of the Modalities of Paradigm Shift}

In the Structure of Scientific Revolutions, a paradigm shift is viewed as an abrupt faith conversion event. Kuhn sheds light only on the preconditions for the shift, the crisis of the reigning paradigm. Motivated by both Bonta's (1979) and Feyerabend's (1975) work we propose that this sudden faith conversion can be further analyzed. In fact, there appear to be three distinct phases in the shift, the first one being the crisis of the existing paradigm. We contend and we shall argue for the view that the second phase is occupied by what Bonta calls the pre-canonical interpretations. Bonta's view is purely descriptive and we suggest that an explanation of what drives this period of pre-canonical interpretations can be found by appealing to Feyerabend's doctrine of anarchic research. The third phase in the transition is marked by the general acceptance of the new paradigm and we shall also turn to discussing the prerequisites for such an acceptance.

\subsection{Crisis in Architectural Interpretation}

For Kuhn the crisis of a paradigm is a crucial point for the evolution of human knowledge. Crises provide the conditions for a passage to "irregular science", the sole period where, as Kuhn himself acknowledges, real novelty is possible. Change of an interpretative paradigm, like that of a scientific one, goes through a phase of diminishing faith to the paradigm. For an architectural work, an established paradigm makes it impossible to "see" the work in any other way. Rules and established practices, in science as well as in architecture, limit the researcher's or architect's freedom. In the latter case, the values one seeks for in a building under study and the elements that express them determine the interpretation. Repetitive or nearly repetitive critical analysis diminishes interest and reference to the building becomes sparser and sparser. In the case of the Barcelona Pavilion, diminishing interest becomes manifest in Zevi's work (Zevi, 1957; Zevi, 1964). Having played a significant role in the establishment of a dominant interpretation during the fifties, it is remarkable that in the book Zevi publishes in 1964 there is very little reference to the pavilion.

This weakness of a Paradigm to produce novel evaluations for a work is not an anomaly, one of many that might lead to crisis. To the contrary and as in science too, applications of the paradigm may lead to extensions and refinements of 
it. Ensuing crisis is not the issue. Lack of interest in research and interpretative attempts however, when the paradigm has lost momentum, is a significant issue. If nothing novel is offered, then this becomes a cause for crisis and the scientific or architectural community is becoming prepared to endorse some new paradigm. Negative criticism results, as a consequence. This is quite visible in the case of the pavilion in the seventies, when the design principles are questioned. In essence, it is not the pavilion per se that is under critique. It is rather the interpretative paradigm that provided the framework which led to regarding the pavilion as a masterpiece, one that "the twentieth century could put forth for comparison with the glorious past". Both Hughes (1976) and Brolin (1976), in 1976, advance criticism that is no less than a manifestation of crisis for the dominant paradigm. Crisis, per se, as Kuhn holds, is not sufficient for a paradigm shift, a scientific revolution.

\subsection{Anarchic Research and Emergence of Alternative Interpretations}

According to Feyerabend (1975), the only principle that does not prevent progress is the principle: everything goes. He holds that research activity must pursue various directions, investigating the potential of theories that may be incommensurable with received theoretical assumptions. It is not the research outcomes that may be produced that matter, but it is rather the creation of an atmosphere of multiplicity. Feyerabend proposes the idea of anarchic research, without any restriction to particular periods, phases or circumstances. He intends it to apply even for normal science. What we propose is that Feyerabend's views are especially pertinent during the transition period, one initiated by a state of crisis in the existing paradigm. It is during this period that established rules are rejected and research becomes an unconstrained "experiment". In architecture this is reflected in the simultaneous emergence of a number of antagonizing pre- canonical interpretations. New interpretative schemes are sought for and pro- posed, obeying to diverging principles and ignoring established rules. Though this is a noticeable feature manifesting itself even during the normal period of established interpretations, the sheer volume of it in the period following a crisis is remarkable.

Crisis and the proliferation of pre-canonical interpretations are exemplified in the case of the Barcelona Pavilion. During the late sixties and throughout the seventies a number of divergent interpretations are proposed. Nicolini (1970) bases his approach on what he calls the "absolute rigidity" in space organization. Mackay (1968) sees in the pavilion the end of the heroic modernity period, during which architects were inclined to defend socio-political ideals. Koenig (1969) switches the debate to that of a semiotic analysis of the pavilion. In all cases, the views proposed diverge from the dominant paradigm.

\subsection{Establishment of a New Interpretative Paradigm}

Endorsement of a new interpretative paradigm, just like that of a scientific paradigm, is not universal. Not everyone is led to a state of faith-loss for the existing paradigm, despite accumulated anomalies and ensuing doubts. In a sense and despite Kuhn's view of paradigm shift as a (scientific) "revolution", which implies that the preceding paradigm is abolished, paradigms can co-exist in a relation of dominant to dominated, or even in one of antagonism and codominance, both being endorsed by sizable parts of the relevant community. An example for such a situation is found in the case of two Chicago simultaneous architectural exhibitions, in 1976, both bearing on the architecture of the city of Chicago, promoting diverging views on a subject that appears to be common to both. Indeed, one is based on the received, canonical view of the architecture in Chicago, based on Pevsner's (1960) and Giedion's (1941) accounts, while the other, organized by the Chicago Seven group, promotes architectural works in Chicago that were overlooked by the dominant view.

In any case, different and diverging pre-canonical interpretations, put forth in an anarchic fashion, create the conditions for the eventual emergence of a canonical interpretation. This may be one of the pre-canonical interpretations or the result of redefining and unifying more than one of them. Emergence of a canonical interpretation is the result of conference presentations and debates, published articles, exhibitions etc. In any case, the process by which some view or interpretation is endorsed is hardly a process of logical investigation and rational argument and it appears to be more of a "natural selection" process, in Toulmin's sense for an evolutionary epistemology (Toulmin, 1972). The fact that the endorsed interpretation is not a result of rational argument does not mean that the process is arbitrary, as it needs to fulfill two fundamental conditions. It must answer, to a suitable extend, the criticism that has been addressed against the old interpretative paradigm and it must be characterized by breadth of scope. Robert Venturi's (1966) interpretative paradigm, for example, founded on the notions of complexity and contradiction (in architecture), satisfies both conditions. It answers the criticism addressed against the preceding paradigm relating to its holistic and unilateral approach. The notion of purity that contradicts complexity is rejected by Venturi and replaced by elevating a notion of 'contradiction' to the status of an architectural value. 
Challenging an old and endorsing a new interpretative paradigm is a process taking place within a broader process of shift of approach, often triggered by developments in fields external to architecture. A notable example is the infiltration of the architectural interpretative discourse during the seventies and eighties with concepts, ideas and tools originating in linguistics and anthropology, in both cases resting on the semiotic approach of Roland Barthes, Claude Levi-Strauss, Umberto Eco and others. This led to a linguistic and semiotic approach in architectural interpretation, marked by the simultaneous publications of Jencks (1977) and Venturi et al. (1977) in 1977. The widespread establishment of one paradigm over others is largely facilitated by the endorsement of a paradigm by respected scholars, groups, institutes and institutions. Bonta (1979), referring to the issue of the succession of interpretations, identifies such factors and categorizes them as "influencing interpretations".

\section{Conclusion}

This research explored the relations of two different fields, that of architecture and that of contemporary epistemology, or philosophy of science. This investigation of how theory, interpretation and criticism evolve through time is motivated by the understanding that architectural thinking orients architectural action. Our objective has been to articulate a metatheoretical framework for the analysis and understanding of architectural interpretations and criticism, in their development and succession through time. One of our main theses has been that interpretations can be viewed as the analogue, within architecture, of Kuhnean Paradigms (Kuhn, 1962). Architectural interpretative paradigms incorporate value systems, practices and design rules, much as scientific paradigms do. Interpretative paradigms change over time. Just like Kuhn we argued that changes in the interpretative paradigms are not a result of rational argument but that they constitute, as Kuhn suggests, faith conversion events. Unlike Kuhn, regarding the paradigm shift as an abrupt event, we sought to shed light on the period of transition. We distinguished three distinct phases of transition: crisis, antagonism of pre-canonical interpretations (a notion introduced by Bonta) which is best understood in terms of Feyerabend's views of anarchic research and, finally, establishment of a new paradigm. Just like in human sciences and unlike Kuhn's view, we argued on the basis of evidence that distinct interpretative paradigms may overlap or co-exist. The broad endorsement of a paradigm, we proposed, is not a result of rational debate and choice as Laudan holds (Laudan, 1978), and we agree with Kuhn on this point, but a process of prolonged debate and counter-argument that is influenced by the views adopted by respected scholars and institutions.

In this article we omitted our analysis, which the reader can find in the full draft version of the first author's research study (Hartonas, 2016), of the interplay between dominant interpretation(s) and architectural education. In the full draft version, to which we refer the reader for details, we also put our views to test by applying them to a case study, that of the transition from the expressionist to the spatial interpretative paradigm, as these are exemplified in the case of Gothic architecture. Though not explicitly treated, the views we developed incorporate our stance towards the problem of progress. Though perhaps not as crisp as in the case of hard science, the relativist view that partly underlies our own, is in need of redefining what progress is and in the case of our interest this would involve redefining what progress in architectural interpretation is and how it comes to be achieved. We have indicated in this study the divergence of our views from Laudan's views of progress (Laudan, 1978) as a result of rational choices made by scientists. The issue of progress in architectural interpretation and criticism deserves to be treated in a separate study and we shall be content with indicating that, to the extent discussed in the present study, progress appears to be 'measurable' by

(a) enlarged breadth of scope and (b) internal coherence of the interpretative paradigm. The question of how progress is achieved is the same as the question of how paradigms come to change. As hinted in this study, this appears to be a process that is perhaps best understood in evolutionary terms, after Toulmin.

\section{References}

Anderson, S. (1984). ArChitectural Research Programmes in the Work of Le Corbusier. Design Studies, 5, 146-150.

Banham, R. (1969). THe Architecture of the Well-tempered Environment. The University of Chicago Press.

Banham, R. (1960). Theory and Design in the First Machine Age. Praeger Publishers.

Broadbent, G. (1993). Design in Architecture: Architecture and the Human Sciences. John Wiley \& Sons.

Blake, P. (1960). The Master Builders. Alfred A. Knopf.

Bonta, J.P. (1975). An Anatomy of Architectural Interpretation: A Semiotic Re-view of the Criticism of Mies Van Der Rohe's Barcelona Pavilion. Editorial Gustavo Gili. 
Bonta, J.P. (1979). Architecture and its Interpretations: A Study of Expressive Systems in Architecture. Lund Humphries.

Broadbent, G. (1970). Meaning into Architecture. In Jencks C \& Baird G (Eds). Meaning in Architecture. George Braziller Editions.

Brolin, C. B. (1976). The Failure of Modern Architecture. Van Nostrand Reinhold.

Feyerabend, P. (1975). Against Method. New Left Books.

Fitch, J.M. (1961). Architecture and the aesthetics of plenty. Columbia University Press.

Fitch, J.M. (1976). ArchitectUral Criticism: Trapped in its Own Metaphysics. Journal of Architectural Education, 29(4), $2-3$.

Giedion, S. (1941). Space, Time and Architecture: The Growth of a New Tradition. Harvard University Press.

Hartonas, D. (2016). Interpretation \& Paradigm in Architectural Metatheory. Undergraduate diss., National Technical University of Athens.

Hitchcock, H.R. (1929). Modern Architecture: Romanticism and Reintegration. Payson and Clarke.

Hitchcock, H.-R. (1958). Architecture: Nineteenth and Twentieth Centuries. Penguin Books.

Hughes, R. (1976). An architecture of Grandeur. Horizon, 18(1), 64-77.

Jencks, C. (1977). The Language of Post-Modern Architecture. Rizzoli.

Johnson, P.A. (1994). The Theory of Architecture: Concepts, Themes and Practices. John Wiley \& Sons.

Koenig, G.K. (1969). Gropius o Mies. Casabella, 342, 34-39.

Kuhn, T. (1962). The Structure of Scientific Revolutions. University of Chicago Press.

Lakatos, I. and Musgrave, A., (eds). (1970). Criticism and the Growth of Knowledge: Proceedings of the International Colloquium in the Philosophy of Science, London, 1965. Vol. 4. Cambridge University Press.

Lakatos, I. (1978). The Methodology of Scientific Research Programmes. Cambridge University Press.

Laudan, L. (1978). Progress and its Problems: Towards a theory of scientific growth. University of California Press.

Mackay, D. (1968). De la revolution espartaquista al Pabellon de Barcelona. In Serra d'Or, October 1968.

Masterman, M. (1970). The Nature of a Paradigm. In Lakatos I \& Musgrave A (Eds). Criticism and the Growth of Knowledge: Proceedings of the International Colloquium in the Philosophy of Science, London, 1965 (pp. 59 90). Cambridge University Press.

Nicolini, R. (1970). Mies, l'epilogo. In Bauhaus, a monographic issue of “Controspazio”, 2(4-5).

Overington, M. (1977). The Scientific Community as Audience: Toward a Rhetorical Analysis of Science. Philosophy \& Rhetoric, 10(3), 143-164.

Percival, K. (1979). The Applicability of Kuhn's Paradigms to the Social Sciences. The American Sociologist, 14(1), 28-31.

Pevsner, N. (1960). An Outline of European Architecture. Penguin.

Popper, K. (1959). The Logic of Scientific Discovery. Hutchinson \& Co Press.

Summerson, J. (1963). Heavenly mansions and other essays on architecture ( $\left.2^{\text {nd }} \mathrm{ed}\right)$. W.W. Norton.

Toulmin, S. (1972). Human Understanding. Oxford University Press.

Tzonos, P. (1984). Four Value-Systems in the Theory of Contemporary Architecture (in Greek). Ziti Publications.

Tzonos, P. (1972). Evolution of the Theory of Contemporary Architecture and Architectural Education (in Greek edition). Technical Chronicles, December.

Venturi, R. (1966). Complexity and Contradiction in Architecture. The Museum of Modern Art Press.

Venturi, R., Scott-Brown, D. and Izenour, S. (1977). Learning from Las Vegas. MIT Press.

Zevi, B. (1957). Architecture as Space: How to Look at Architecture. Trans. Milton Gendel. Horizon Press.

Zevi, B. (1964). Architettura in nuce. Instituto per la Collaborazione Culturale.

Cite this article as: Dimitris Hartonas and Nikolaos I on Terzoglou (2021). Interpretation and Paradigm in Architectural Metatheory. International Journal of A rchitecture and Planning. 1(2), 28-36. doi: 10.51483/ IJA RP.1.2.2021.28-36. 